\title{
Integrated modelling for understanding watershed development impacts on social and biophysical systems.
}

\author{
Merritt, W.S. ${ }^{1}$, V.R. Reddy ${ }^{2}$, K.V. Rao ${ }^{3}$, P. Pavelic $^{4}$, S. Ahmed ${ }^{5}$, R. Ranjan ${ }^{6}$, B.F.W. Croke ${ }^{1,7}$, and G. J. \\ Syme $^{8}$ \\ ${ }^{I}$ Integrated Catchment Assessment and Management (iCAM) Centre, The Fenner School of Environment and \\ Society, The Australian National University, Canberra, ACT, 0200, Australia \\ ${ }^{2}$ Livelihoods and Natural Resource Management Institute (LNRMI), Hyderabad, 500 067, Andhra Pradesh, \\ India \\ ${ }^{3}$ Central Research Institute for Dryland Agriculture (CRIDA), Hyderabad, 500 059, Andhra Pradesh, India \\ ${ }^{4}$ International Water Management Institute, Pantacheru, 502 324, Andhra Pradesh, India \\ ${ }^{5}$ National Geophysical Research Institute (CSIR-NGRI), Hyderabad, 500 606, Andhra Pradesh, India \\ ${ }^{6}$ Climate Risk CoRE and Graduate School of the Environment, Macquarie University, Sydney, NSW, 2109, \\ Australia \\ ${ }^{7}$ Department of Mathematics, The Australian National University, Canberra, ACT, 0200 \\ ${ }^{8}$ Department of Planning, Edith Cowan University, Joondalup, WA, 6027, Australia
}

Email: wendy.merritt@anu.edu.au

\begin{abstract}
The intention of watershed development (WD) programs in India is to improve the livelihoods of people and preserve the natural resource base, particularly in areas where water scarcity limits the development potential of rural communities. In practice, there are many complications to implementing WD programs in an effective and equitable way for all people within and between villages in a catchment. Our understanding of the potential implications of a program is often limited by the way in which we investigate the biophysical-social-economic system. Two common failings are (a) not properly considering the importance of the place, scope and scale of a problem and (b) using a disciplinary approach to make conclusions about the system as a whole.

This paper discusses how we are addressing these issues as part of an integrated assessment project looking at WD in the state of Andhra Pradesh, India. The multi-disciplinary project team includes agronomists, economists, environmental modellers, groundwater and surface water hydrologists, and social scientists who together are aiming to develop a holistic understanding of the impacts of WD on biophysical, social and economic systems. Key to the project philosophy is the inclusion of government representatives, communities, and non-government organisations (NGOs) in developing the researchers' understanding of the issues and complexities associated with WD and the critical questions that need addressing by the project.
\end{abstract}

An integrated model is being developed that will incorporate crop production water use and hydrological (surface water and groundwater) models in addition to knowledge gained from extensive household surveys in villages in two case study catchments. The household surveys were developed based on discussions with NGOs working with the rural communities in Andhra Pradesh and are being used to examine economic and social outcomes (positive and negative) of WD for households. Measures of equity and resilience are being developed to measure differences in outcomes between villages (e.g. upstream, downstream) and within villages (e.g. income groups, gender, land ownership, etc).

Keywords: Watershed development (WD), integrated modelling, sustainable livelihoods 


\section{INTRODUCTION}

Agricultural and livestock production are major sources of livelihood for much of India's rural communities (Mudrakartha, 2007). Traditionally, investment in India's agricultural lands has focused on irrigated and high-potential rainfed areas (Rockström et al. 2010). Whilst large productivity gains have been achieved in those areas, issues of poor productivity, poverty, food insecurity and environmental degradation remain widespread in the dryer rainfed areas where much of the rural poor live (Fan et al. 2000). Researchers and governments are increasingly focusing on these areas where it is argued that government and other investment will have greater impact on livelihoods (e.g. Rockström et al. 2010).

Watershed Development (WD) has been widely promoted and instigated in the semi-arid agricultural areas of India as a means to improve the livelihoods of rural communities (Reddy et al. 2004a). WD programs implement a range of technical interventions like soil and water conservation and the provision of water harvesting structures which are intended to improve livelihoods through increased water availability and land productivity. Whilst benefits of WD programs have included increased water availability, crop productivity and incomes as well as more rural employment, many authors have noted the missed opportunities and common failures of WD including inequitable distribution of benefits between richer and poorer households (e.g. Reddy et al. 2004b), over-use of groundwater (e.g. Reddy et al. 2004b, Wani et al. 2008, Calder et al. 2008a) or conflicts between upstream and downstream farmers (Calder et al. 2008a).

Over recent years, with awareness of the problems associated with WD, there has been considerable effort made to evaluate the effectiveness of WD programs in achieving their primary aim - the sustainable improvement of people's livelihoods. Much of this effort has been focused on the scale at which WD programs have been implemented, although there is increasing recognition of the need to evaluate impacts on resources and communities outside of the WD implementation area (e.g. Wani et al. 2008). This paper outlines an integrated modelling approach being developed to explore environmental, economic, equity and social dimensions of WD development in Andhra Pradesh.

\section{THE IMPACTS OF MESO-SCALE WATERSHED DEVELOPMENT IN ANDRA PRADESH}

Funded by the Australian Centre for International Agricultural Research (ACIAR), a multidisciplinary team is examining scale issues associated with WD in Andhra Pradesh. WD projects in India are typically implemented in small watersheds $\left(<50 \mathrm{~km}^{2}\right)$ to match with local communities (Barron and Noel, 2011). WD implementation at this scale has the advantage of facilitating intensive activities and participatory processes with local stakeholders. Many authors have recognised the potential negative impacts on communities downstream from the WD activities including reduced flows into downstream reservoirs (Sakthivadivel and Scott, 2005) or out of catchments (Calder et al. 2008a). Given these externalities, and the need for watershed programs to overlap with the administrative unit that delivers services (FAO, 2006), it has been suggested that the design of WD programs consider upstream-downstream relationships. This implies up-scaling WD and Barron and Noel (2011) suggest that the meso-scale is where biophysical impacts such as water quantity and quality can be controlled and impacts of WD are still felt by local stakeholders. In this paper we consider meso-scale to be approximately $100 \mathrm{~km}^{2}$ in area.

This project - referred to as the meso-scale project from here-on-in - aims to evaluate the positive and negative impacts of WD across the landscape looking at biophysical impacts along an upstream-downstream continuum and economic and social consequences (including equity) within and between villages. The temporal scale of analysis spans the short-term economic outcomes to the longer term implications for natural and social capital (Syme et al. 2010).

\subsection{Study Areas}

The government of Andhra Pradesh - a state on the south-eastern coast of India - identifies WD as a means of promoting sustainable livelihoods and has implemented many thousands of WD projects over the last three decades (Reddy et al. 2004b). Andhra Pradesh is one of the drier states in India with around $70 \%$ of its agricultural land being rainfed systems. The inland regions of the state tend to be drought prone which exacerbates the plight of the rural poor. For example, the Anantapur district is highly drought prone (meteorologically and agriculturally) with the least rainfall of any district in the state, a generally low resource base, and little capacity for surface irrigation. Consequently, the district has a high level of both poverty and family debt (Reddy et al. 2004b). 
The meso-scale project focuses on selected villages from three hydrological units (subcatchments) in Andhra Pradesh (Figure 1): Peethuru Vagu in the Prakasam district, and Vajrala Vanka and Maruva Vanka which are both located partly in the Anantapur and Kurnool Districts. The Maruva Vanka hydrological unit is located downstream of Vajrala Vanka. Three villages were selected as study areas in the Peethuru Vagu unit, two villages were selected in the Vajrala Vanka unit and one

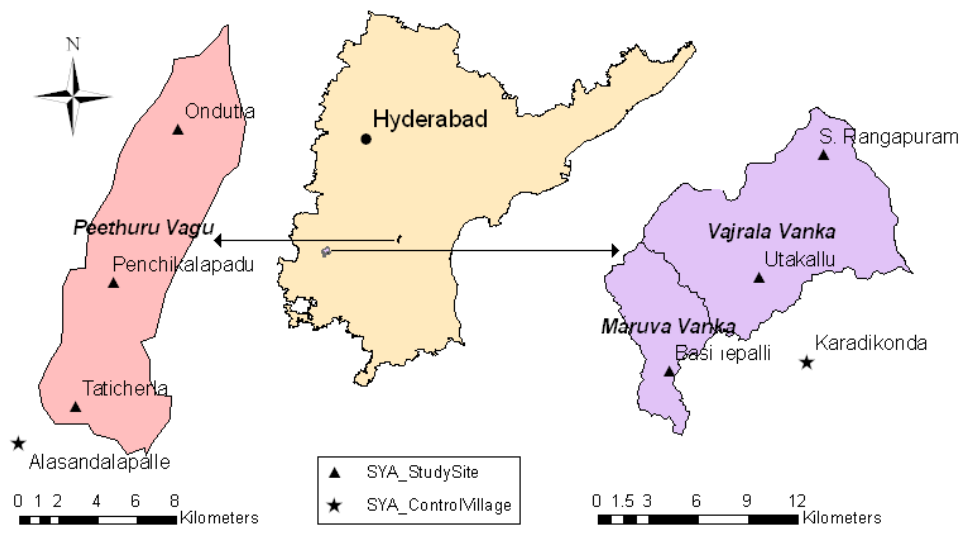

Figure 1. Meso-scale project study areas. village from the Maruva Vanka unit. Each village has undergone WD and also the Andhra Pradesh Farmer Managed Groundwater Systems (APFMGS) project. APFMGS was designed to promote sustainable management of groundwater by farmers through building their skills and knowledge (Source: http://www.fao.org/nr/water/projects andra.html, Accessed $20^{\text {th }}$ June 2011). A control village that had no WD but was part of the APFMGS project was selected from both the Anantupur and Prakasam districts: Karidikonda and Allasandapalli, respectively. The basic features of the study and control villages are listed in Table 1.

Table 1. Characteristics of the study and control villages.

\begin{tabular}{lccccccc}
\hline \multicolumn{1}{c}{ Village } & $\begin{array}{c}\text { Hydrological } \\
\text { Unit }\end{array}$ & $\begin{array}{c}\text { Location } \\
\text { within } \\
\text { subcatchment }\end{array}$ & $\begin{array}{c}\text { Project } \\
\text { Implementing } \\
\text { Agency (PIA) }\end{array}$ & $\begin{array}{c}\text { Year of } \\
\text { Completion }\end{array}$ & $\begin{array}{c}\text { Population } \\
\text { (\% female) }\end{array}$ & $\begin{array}{c}\text { Number of } \\
\text { Households }\end{array}$ & $\begin{array}{c}\text { Scheduled } \\
\text { tribes and } \\
\text { castes (\%) }\end{array}$ \\
\hline S. Rangapuram & Vajrala & Upstream & Government & $1998-99$ & $466(47)$ & 87 & 34 \\
Utakallu & Vanka & Midstream & NGO & $2002-03$ & $1523(47)$ & 320 & 14 \\
Basinepalle & Maruva & Downstream & NGO & $2003-04$ & $1955(49)$ & 425 & 29 \\
Vanka & & & & & & & 15 \\
Taticherla & Peethuru & Upstream & NGO & $2003-05$ & $1139(48)$ & 265 & 10 \\
Penchikalapadu & Vagu & Midstream & NGO & $2007-08$ & $491(49)$ & 114 & 24 \\
Ondutla & & Downstream & NGO & $1998-99$ & $552(48)$ & 121 & 6 \\
Alasandalapalle & Uppa Vagu & Upstream & -- & -- & $581(47)$ & 136 & 6 \\
Karidikonda & Upparavanka & Midstream & -- & -- & $1097(49)$ & 208 & 13 \\
\hline
\end{tabular}

\subsection{Approach}

The meso-scale project is explicitly linking social research with biophysical modelling to develop a holistic understanding of the connected biophysical, social and economic system. The project team includes agronomists, economists, environmental modellers, groundwater and surface water hydrologists, and social scientists who are working on the project components outlined in Table 2.

Representation of the hydrology of the study areas requires consideration of the groundwater and surface water systems in addition to rainwater harvesting structures. Groundwater is the major source of water for agricultural and domestic uses in the semi-arid rural regions of Andhra Pradesh. The basis for the groundwater modelling being done for the meso-scale project is the decision support tool (DST) developed by the Indo-French Centre for Groundwater Research to model mean annual groundwater levels at the basinscale using modelled water balance under variable agricultural and climatic conditions (Dewandel et al. 2010). The surface hydrology model is based on the IHACRES Catchment Moisture Deficit (CMD) model a conceptual model whereby rainfall is partitioned into drainage, evapotranspiration and changes in catchment moisture (Croke and Jakeman, 2004). The rainwater harvesting module considers the relationships between surface runoff into rainwater harvesting structures and percolation from these structures into the groundwater. This works builds on research on the hydrologic impact of water harvesting structures in a $2 \mathrm{~km}^{2}$ catchment in West Bengal (Croke et al. 2008). 
Table 2. Components of the meso-scale project.

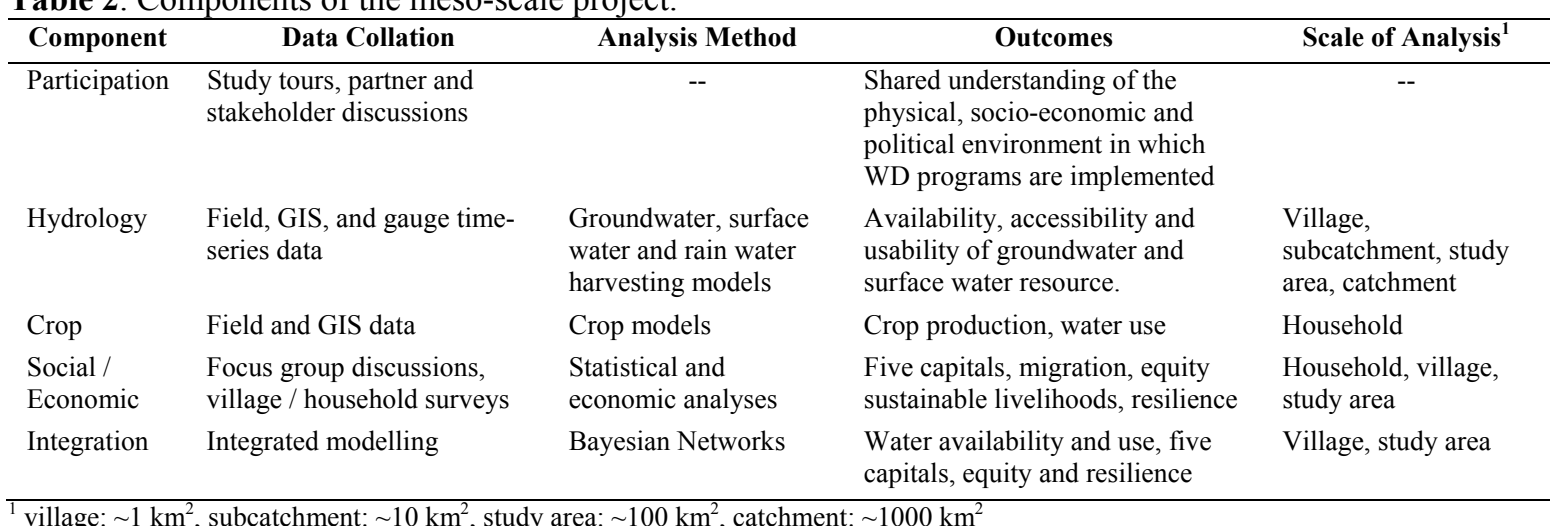

A variety of crops are grown in the study areas, from those with relatively low water requirements (e.g. safflower) to crops like banana and turmeric which require large volumes of water. Whilst the required outputs from the crop modelling are seasonal crop yields and water use, the distribution of rainfall in a season is more critical than the total seasonal rainfall and this will be captured by the crop model being developed for the meso-scale project.

Focus group discussions and village and household surveys are being used to obtain the social and economic data being analysed using the sustainable (rural) livelihoods concept. Sustainable livelihoods has been widely promoted as both an objective of WD and a framework for understanding how people try to improve their lives (Reddy et al. 2004a; Plummer and Armitage, 2007). The premise for the framework is that people have different ways of making a living and try to meet their desired livelihood outcomes by using different forms of capital (Reddy et al. 2004b; Baumann and Sinha, 2001). The assets usually considered are financial, human, natural, physical and social capital, although some authors have proposed political capital as a sixth capital (e.g. Baumann and Sinha, 2001). All forms of capital are linked, although in rural agricultural communities, natural capital (e.g. water, fodder, forest products, etc) is a critical component in determining livelihoods. The survey data is being used to quantify all forms of capital and to develop an indicator of livelihood resilience that identifies the minimum amount of each capital required to sustain livelihoods. The socio-economic component of the meso-scale project is also deriving measures for describing equity issues between locations (i.e. downstream and upstream farmers), between social groups (e.g. gender, castes), or between income or land ownership groups (e.g. landless, marginal landholders, medium area landholders, large area landholders).

The integration component draws on the research outcomes from the project components described above and is developing an integrated model that will explicitly link the socio-economic analyses with the biophysical modelling to allow a holistic representation of the interlinked biophysical and socio-economic systems and to identify the causes of differences in the resilience of households and the communities.

\section{INTEGRATED MODEL}

The integrated model will link biophysical modelling with village scale socio-economic models. The hydrology models provide an assessment by season of the availability of surface and groundwater resources for watershed development and climate scenarios. The crop models simulate yields as well as water use and recharge which feed back into the next season hydrology. Water availability and crop productivity are the main links between the biophysical and socio-economic models. This information in addition to survey data detailing access to land, water and common pool resources as well as network and demographic data is input to the socio-economic models which simulate the response of social and economic indicators for groups differentiated on social (e.g. gender, caste) or economic (e.g. landless, landholders) characteristics. Issues of equity will be assessed by analysing who trade-offs within and between villages. That is, who benefits from WD implementation at whose cost?

Two options exist in how to link the biophysical models to the socio-economic models: (a) full integration where the socio-economic models are dynamically updated with information from scenarios runs of the crop and hydrology models, or (b) outputs from the biophysical models are used as inputs to the socio-economic models. The nature of the integration will depend on the structure of the socio-economic models, how responsive they are and the complexity, scale and linkages of the groundwater, surface water and crop 
models developed by project partners. The rest of this paper outlines early development of the socioeconomic models.

Bayesian Networks (BNs) are the approach being used to develop the socio-economic models. BNs are comprised of an influence diagram that represents links between variables and probabilistic data that describes the nature and strength of the causal links. They offer an alternative to approaches often used in social research that represent causality in isolation of statistical strength or vice versa. BNs have gained considerable popularity in the field of environmental modelling over the last decade as they can represent relationships between the biophysical and societal factors that are central to the success of natural resource management programs. Calder et al. (2008b) describe examples of pilot BNs developed under the Jala Samvardhane Yojana and Sangha and Sujala WD projects. The authors noted that BNs were useful in analysing the data collected as part of the WD projects and could help organisations implementing and evaluating the projects make better use of the information. Ticehurst et al. (2011), after investigating the potential for BNs to enhance understanding of the influence of social and economic factors on landholder decision-making, noted that, once developed, BNs can be highly useful for structuring, clarifying and communicating to stakeholders the results of the investigation, more so than was achievable with 'conventional' statistical analyses (e.g. regression models, non-parametric statistics).

BNs are being used to implement the sustainable livelihoods framework whereby the levels of five capitals define resilience to droughts or other shocks (Figure 2). The structure of the influence diagrams for each of the five capitals is being developed based primarily on the household survey data. The first round of data collection has been collated for 564 households across the sample villages. This data is being used to develop and refine the structure and populate the BNs. To date, prototype models have been developed for human capital and natural capital. These models are currently being critically reviewed with the project team and will be used, together with subsequent rounds of data, to further refine the model structure and relationships.

In the draft human capital subset of the BN (Figure 3a), human capital is related to a number of variables including the health, skill and education levels for the households in each village. Health is related to four variables: access to health services, the number of household members over 50 years in age, education and the adequacy of drinking water. Given data limitations no variable reflecting dietary intake is currently connected to health. The outcome variable Human Capital is defined in terms of having sufficient or good education (HK1) and/or health (HK2) and/or skills (HK3). In the BN, WD affects human capital through the direct impacts on skills and through the influence of drinking water adequacy on health. Drinking water adequacy is a function of both access and quality. Human capital is most sensitive to education, then health and skills. Health is most strongly influenced by the adequacy of drinking water - four times more than the next most sensitive input variable, Education (Figure 3b [left panel]). When the adequacy of drinking water is low, 69\% of sampled households (combining data from all villages) reported that less than $25 \%$ of the household was healthy compared with $15 \%$ when the adequacy of water is good (Figure $3 b$ ). Human capital is relatively insensitive to WD with little change in the model before and after program implementation observed across all villages. Greater impacts are expected for natural and financial capital, in particular.

\section{DISCUSSION AND CONCLUSIONS}

The issue of WD in India is a classic example of a complex or 'wicked' environmental and social problem. Rural poverty in drought prone areas remains a big concern despite large investments from Indian government and non-government organisations. Questions have been raised over the effectiveness of WD in achieving both environmental and social outcomes. Positive benefits have been observed at small spatial scales and/or in successful watersheds that represent a minor proportion of all WD programs (Wani et al. 2008). Negative impacts incurred from WD have included impacts on downstream farmers, over-exploitation of natural resources such as groundwater and a failure to deliver benefits to those most in need.

The integrated model described in this paper is being constructed to support the analysis of the spatial and temporal impacts of WD on the resilience and sustainability of both people's livelihood and natural capital (especially water resources). Many of the biophysical, economic and social indicators being examined have previously been used to measure the effects of WD and, with appropriate design of new WD programs, are measurable before, during and after implementation. The approach being implemented is necessary to 
develop a holistic understanding of interactions between land, water, and people and draw appropriate conclusions as to the causes of differences in the resilience of households and the communities.

A key challenge for the meso-scale project is to produce research outcomes and modelling tools that transcend catchment specificity and inform future WD and planning across Andhra Pradesh. Given the requirement for institutional change in moving from micro to meso WD and the consequent need for transparent decision making the early involvement of landholders and their organizations in the design of a simple integrated tool is necessary. At the state and central government levels there is a need for an evaluative tool to assist in designing the appropriate scale for WD to ensure sustainable whole-of-catchment planning. Key to the meso-scale project is the inclusion of government representatives, communities, and non-government organisations (NGOs) in developing the researchers' understanding of the issues and complexities associated with WD and the critical questions that need addressing by the project. Our aspirations are that the research outcomes and products (e.g. groundwater, crop and integrated models) are adopted, used and adapted by government and non-government agencies involved in WD in India.

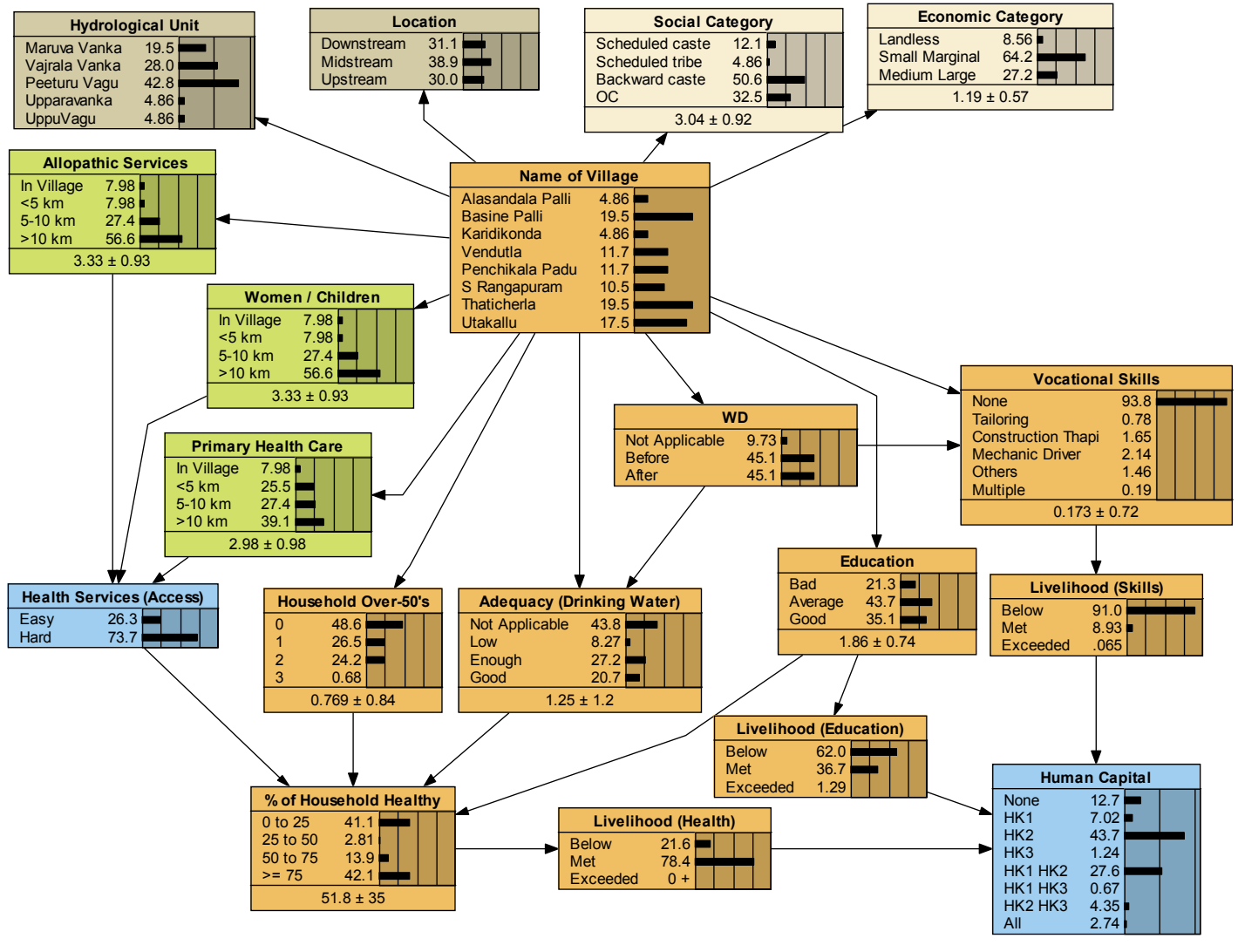

(a)
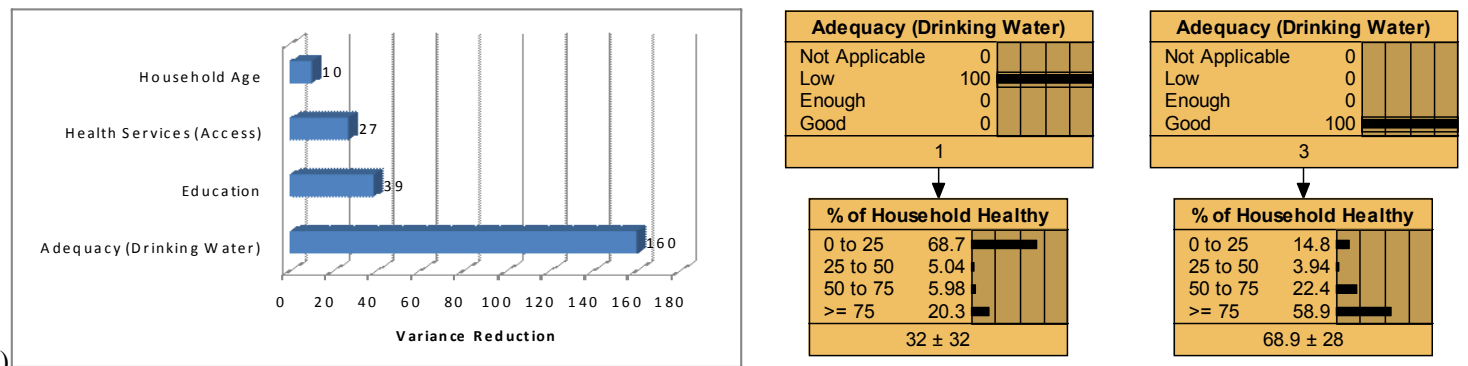

Figure 3. Human capital component BN: (a) influence diagram and (b) sensitivity of \% of Household Healthy to the input variables (left), and the effect of low and high adequacy of drinking water on household health (middle and right, respectively).

\section{ACKNOWLEDGMENTS}

This research is funded by the Australian Centre for International Agricultural Research. Many thanks to Mr. Sreedhar Acharya from the International Water Management Institute for providing the GIS data in Figure 1. 


\section{REFERENCES}

Barron, J. and S. Noel, (2011). Valuing soft components in agricultural water management interventions in meso-scale watersheds: A review and synthesis. Water Alternatives, 4, 145-154.

Baumann, P and S. Sinha, (2001). Linking development with democratic processes in India: Political capital and sustainable livelihoods analyses. Natural Resource Perspectives, The Overseas Development Institute.

Calder, I., A. Gosain, M.S.R.M. Rao, C. Batchelor, M. Snehalatha, and E. Bishop, (2008a). Watershed development in India. 1. Biophysical and societal impacts. Environment, Development and Sustainability, 10, 537-557.

Calder, I., A. Gosain, M.S.R.M. Rao, C. Batchelor, J. Garratt, and E. Bishop, (2008b). Watershed development in India. 2. New approaches for managing externalities and meeting sustainability requirements. Environment, Development and Sustainability, 10, 427-440. Croke, B.F.W., and A.J. Jakeman, (2004). A catchment moisture deficit module for the IHACRES rainfall-runoff model. Environmental Modelling and Software, 19, 1-5.

Croke, B.F.W. and A.J. Jakeman, (2004). A catchment moisture deficit module for the IHACRES rainfall runoff model. Environmental Modelling and Software, 19, 1-5.

Croke, B., N. Norrish, A. Kumar, A. Islam, P. Dey, P. Cornish, S. Kumar, and J. Ghosh, (2008), Insights into catchment behaviour for water harvesting assessment in the East India Plateau. In Miquel Sànchez-Marrè, Javier Béjar, Joaquim Comas, Andrea E. Rizzoli, Giorgio Guariso (Eds.), Proceedings of the iEMSs Fourth Biennial Meeting: International Congress on Environmental Modelling and International Environmental Modelling and Software Society, Barcelona, Catalonia, July 2008, Vol 1, 454-461.

Dewandel, B., J. Perrin, S. Ahmed, S. Aulong, Z. Hrkal, P. Lachassagne, M. Samad, and S. Massuel, (2010) Development of a tool for managing the groundwater resources in semi-arid hard rock regions: Application to a rural watershed in South India. Hydrological Processes, 24, 2784-2797.

Fan, S., P. Hazell, and T. Haque, (2000). Targeting public investments by agro-ecological zone to achieve growth and poverty alleviation goals in rural India. Food Policy, 25, 411-428.

Food and Agriculture Organisation of the United Nations, (2006). The new generation of watershed management programmes and projects, FAO Forestry Paper, 150, 128pp.

Mudrakartha, S, (2007). To Adapt or Not to Adapt: The Dilemma between Longterm Resource Management and Short-term Livelihood. In The Agricultural Groundwater Revolution: Opportunities and Threats to Development (M. Giordano and K.G. Villholth), CAB International.

Plummer, R. and D. Armitage, (2007). A resilience-based framework for evaluating adaptive comanagement: Linking ecology, economics and society in a complex world. Ecological Economics, 61, 6274.

Reddy, V.R, M.G Reddy, S. Galab, J Soussan and O. Springate-Baginski, (2004a). Participatory Watershed Development in India: Can it Sustain Rural Livelihoods? Development and Change, 35, 297-326.

Reddy V.R., M.G. Reddy, and J. Soussan, (2004b). Water and poverty: a case of watershed development in Andhra Pradesh, India. In Water and Poverty - The Realities. Asian Development Bank. http://www.adb.org/Documents/Books/Water_for_All_Series/Water_Poverty_Realities/Water_05.pdf

Rockström, J., L. Karlberg, S.P. Wani, J. Barron, N. Hatibu, T. Oweis, A. Bruggeman, J. Farahani, and Z. Qiang, (2010). Managing water in rainfed agriculture - The need for a paradigm shift. Agricultural Water Management, 97, 543-550.

Sakthivadivel, R. and C.A. Scott, (2005). Upstream-downstream complementarities and tradeoffs: Opportunities and constraints in watershed development in water scarce regions. In Watershed Management Challenges: Improving Productivity, Resources and Livelihoods (B.R. Sharma, J.S. Samra, C.A. Scott and S.P. Wani). International Water Management Institute, 173-185.

Syme, G.J., B.F.W. Croke, V.R. Reddy, R. Ranjan, P. Pavelic, N. Herron, K.V. Rao and S. Ahmed, (2010). Integrated assessment of meso-level watershed development: Progress of an integrated evaluation project in Andhra Pradesh. Third International Conference on Hydrology and Watershed Management, February 3-6, Hyderabad, India.

Ticehurst, J.L., A. Curtis, and W.S. Merritt, (2011). Using Bayesian Networks to complement conventional analyses to explore landholder management of native vegetation. Environmental Modelling and Software, 26, 52-65.

Wani, S.P., P.K. Joshi, K.V. Raju, T.K. Sreedevi, M.J. Wilson, A. Shah, P.G. Diwakar, K. Palanisami, S. Marimuthu, Y.S. Ramakrishna, S.S.S. Meenakshi, and M. D’Souza, (2008). Community watershed as growth engine for development of dryland areas - executive summary: a comprehensive assessment of watershed programs in India. Patancheru 502 324, Andhra Pradesh, India: International Crops Research Institute for the Semi-Arid Tropics. $36 \mathrm{pp}$. 